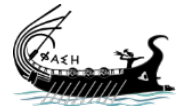 \\ journal.phaselis.org \\ open 2 access journals}

Atıf Düzeni

Ü. Demirer, "Kibyra Kazılarından Yeni Bir Buluntu Grubu: Göz Aplikleri”. Phaselis II (2016) 133-

148. DOI: 10.18367/Pha.16008

Geliş Tarihi: 5.05.2016 | Kabul Tarihi: 25.05.2016 | Online Yayın Tarihi: 22.06.2016

Editörya Phaselis Research Project

www.phaselis.org
Kibyra Kazılarından Yeni Bir Buluntu Grubu: Göz Aplikleri

\author{
A New Group of Finds from the Kibyra Excavation: Eye \\ Appliques
}

Ünal DEMIRER

PHASELIS: Disiplinlerarası Akdeniz Araştırmaları Dergisi'nde bulunan içeriklerin tümü kullanıcılara açık, serbestçe/ücretsiz "açık erişimli" bir dergidir. Kullanıcılar, yayıncıdan ve yazar(lar)dan izin almaksızın, dergideki makaleleri tam metin olarak okuyabilir, indirebilir, dağıtabilir, makalelerin çıktısını alabilir ve kaynak göstererek makalelere bağlantı verebilir.

PHASELIS: Disiplinlerarası Akdeniz Araştırmaları Dergisi uluslararası hakemli elektronik (online) bir dergi olup değerlendirme süreci biten makaleler derginin web sitesinde (journal.phaselis.org) yıl boyunca ilgili sayının içinde (Volume II: Ocak-Aralık 2016) yayımlanır. Aralık ayı sonunda ilgili yıla ait sayı tamamlanır.

Dergide yayımlanan eserlerin sorumluluğu yazarlarına aittir. 


\title{
Kibyra Kazılarından Yeni Bir Buluntu Grubu: Göz Aplikleri
}

\author{
A New Group of Finds from the Kibyra Excavation: Eye Appliques
}

\author{
Ünal DEMIRER*
}

Öz: Burdur ili Gölhisar ilçesi sınırları içinde bulunan Kibyra antik kentinde sürmekte olan kazılarda, nekropolis alanı çevresi ve mezar odalarında yeni bir buluntu gurubu açığa çıkmışır. Kaçak kazılarla karıştııı ış olan kontekstlerde kafatasları üzerinde veya göz çukurları içinde bulunmamış olmalarına rağmen, iskeletler ve ölü yatakları yakınlarında bulunan oval formlu bu ilk buluntular "göz apliği" olarak tanımlanmıştır. Çalışmalar sürdükçe, apliklerin kare formlu tiplerinin de bulunduğu, çok canlı renklerle boyanmış oldukları anlaşılmışır. İ̧levleriyle ilgili kesin bir kanıya varmak için yapılan köken ve benzer araştırmaları sırasında, ölü gömme törenlerinde cesedin gözlerine objeler koyma geleneğinin MÖ VI. bine dek indiği görülmektedir. Bu çalışmada, MS II. yüzyılda kullanım görmüş olan Kibyra mezarlarında bulunan ve "göz apliği" olarak tanımlanan pişmiş toprak aplikler yanında figürlü pişmiş toprak veya metal örneklerin de kullanılmış olabileceği düşüncesiyle düzenlenen katalog ile de ardıl çalışmalara katkı sağlamak amaçlanmıştır.

Anahtar Sözcükler: Kibyra · Mezar Buluntuları · Ölü Gömme Adetleri · Göz Aplikleri

Abstract: In excavations at the ancient city of Kibyra, which is situated in the Gölhisar township of Burdur province, new finds have been made in the burial chambers and within the necropolis context. Although the strata and contexts are mixed due to illegal excavations, and even though they have not been found located on the eye sockets or around the skulls, these initial oval-shaped finds, recovered near to the skeletons or to the kline, the bed for the deceased, are described as "eye-appliques". As work continues, it is now understood that there are also, in addition to those of oval shape, a square-shaped type, and that these examples are painted in very bright colours. During the studies conducted to determine the origin and function of this type of find and the related material it was found that the tradition of placing objects on the eyes of the deceased dates back to the $6^{\text {th }}$ millennium. The aim of this study is to contribute to future work on thissubject through providing a catalogue, with the idea that, in addition to the terracotta finds defined as "eye appliques", figurative terracotta or metal examples were also employed for the same purpose within the $\|^{\text {nd }}$ century A.D. Kibyra necropolis.

Keywords: Kibyra · Grave Goods · Burial Rituals · Eye Appliques

Antikçağda Kibyratis olarak adlandırılan bölgenin başkenti konumundaki Kibyra kenti, günümüzde Burdur ili Gölhisar ilçesi sınırları içinde yer almaktadır. Kentte Burdur Müzesi öncülüğünde 2006 yııında başlatılmış olan kazılar, 2010 yılından itibaren Mehmet Akif Ersoy Üniversitesi Arkeoloji Bölümü öğretim üyesi Yrd. Doç. Dr. Şükrü Özüdoğru başkanlığındaki bir ekip tarafından sürdürülmektedir ${ }^{1}$.

\footnotetext{
* Yrd. Doç. Dr., Mehmet Akif Ersoy Üniversitesi, Gölhisar Meslek Yüksek Okulu, Mimarlık ve Şehir Planlama Bölümü, Burdur. demirerunal@gmail.com

1 Özüdoğru 2014a, 172-173.
} 
2010 yılı çalışma sezonunda, kente doğudan girişi sağlayan ve her iki yanında mezarlar bulunan Nekropolis Yolu başlangıcındaki Doğu Nekropolis alanındaki YOM (Yeraltı Oda Mezarı) 9 olarak numaralandırılan mezarda ${ }^{2}$ M. Şimşek tarafından kazı çalışmaları yapılımıştır. Araştırmalar sırasında, ilerideki yıllarda çok sayıda benzeri ortaya çıkacak yeni bir buluntu grubunun ilk örnekleri ele geçmiştir. İrisi kabarık, oval formlu ve üzerlerinde çok az boya kalıntısı görülen bu iki pişmiş toprak buluntu, boyut ve şekil olarak göze benzediği ve çift halinde ölü yatağı üzerinde bulunduğu için "göz apliği" olarak tanımlanarak belgelenmiştir (Kat. No. 1-2).

2013 yılında, özellikle Doğu Nekropolis'teki Anıt Mezar ve çevresindeki temenos'lar yanında altlarındaki oda mezarlarda çalışmalara devam edilmiştir. Bu alanlarda yapılan kazılarla, pişmiş toprak apliklerin mezar hediyesi veya gömü kültüyle ilgili önemli bir örge olarak, Kibyra mezarlarında sıklıkla kullanılmış olduğu anlaşımış ve iki yıllık çalışma sürecinde bu ilginç buluntular hakkında bir tartışma başlatacak yeterlikte örnek ele geçmiştir.

Anıt Mezar Güney Temenos YOM 10 ve YOM 11'de bulunan iki örnek (Kat. No. 3-4), apliklerin çok canlı renklerle boyanmış olduğunu göstermiştir. Üzerinde boya kalıntısı korunagelmiş olan tüm örneklerde, şaşırtıcı bir özellik olarak, sabit bir renk seçimi olduğu görülmüştür: Oval veya kare bütün örneklerde çerçeve bölümü altın yaldız, yüksek iç bölüm ise parlak kırmızı boyalıdır.

Aynı yıl, aynı mezarda ölü yatağı üzerinde ele geçen bir çift buluntu ile, apliklerin ileride görüleceği gibi, kare şekilli ikinci bir tipinin daha olduğu anlaşılmıştır (Kat. No. 16-17). Yine aynı alanda bulunan, portreli bir diğer pişmiş toprak örnek (Kat. No. 25) yanında, Odeion kazıları sırasında yüzeyde bulunan bakır alaşımlı iki buluntu (Kat. No. 26-27), benzer işleve sahip değişik materyal ve şekle sahip başka örnekler de olabileceğini göstermiştir.

Grup içinde bir sınıflama yapıldığında, buluntuların oval (Kat. No. 1-15) ve kare (Kat. No. 1624) olmak üzere iki ana formda olduğu; portreli, ovoid-yumurtamsı veya pişmiş toprak dışındaki metal, kemik, cam gibi farklı malzemelerle üretilmiş olası benzer örneklerin "diğerleri" olarak (Kat. No. 25-27) sınıflandırılabileceği görülmektedir. Oval örneklerin genişliği 3,2-4,5 cm; yüksekliği 2,7-3,8 cm; kalınlıkları ise 0,6-1,1 cm arasında, birbirine yakın ölçülerle değişmektedir. Kare örneklerde, kare kenarı 3-4 cm, kalınlık ise 0,4-0,7 cm arasında değişmektedir; çerçeve içindeki yükselti, kesik piramit tabanı formundadır. Tüm örnekler kalıp tekniğiyle üretilmişlerdir ve çamurun kalıba bastırılması sırasında, üreten seramikçinin parmak izleri apliklerin arka yüzeyinde görülmektedir.

Yaygın olarak, mezarların tümünde adak eşyası olarak pişmiş toprak kaplar, unguentarium'lar, sikkeler ve kandiller bulunmuştur. Cinsiyet belirleyen yegâne buluntular, YOM 9' da oval aplikler yanında bulunan bir küpeden ve YOM 11'de oval, kare ve portreli aplikler yanında bulunan kemik saç iğnesi ve YOM 12' deki oval ve kare formlu apliklerle bulunan kemik saç kıskacından ibarettir. Geç antikçağdaki mezar soygunları nedeniyle kontekstlerde oluşan karışıkıklar nedeniyle, apliklerden hiç biri kafataslarındaki göz boşlukları veya yakınında bulunamamıştır. Bu nedenle, mezarlarda bulunan iskeletler üzerinde sürmekte olan antropolojik çalışmalar tamamlansa bile, apliklerin kullanımında formlar ile cinsiyetler arasında bağ kurmak olası değildir.

Ölü gömme törenlerinde, göz boşluklarına farklı materyallerden yapılmış nesneler konulması,

Şimşek 2013, 68 lev. II, harita 2. Eserleri gün yüzüne çıkaran Uzman M. Şimşek'e, çalışma izni veren Yrd. Doç Dr. Ş. Özüdoğru’ya, temizlik, koruma ve belgeleme çalışmalarını tamamlayan Öğr. Gör. S. Akgül Özarslan’a çok teşekkür ederim. 


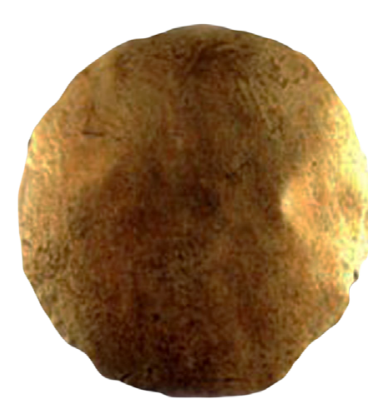

Fig. 1

Köşk Höyük'te siyah taştan iki göz ile bulunan kafatasının kanıtladığı gibi, MÖ VI. bine dek inen bir gelenek olmalıdır ${ }^{3}$. Ölünün yüzünün altın bir maskeyle ${ }^{4}$ veya gözlerinin altın plakalarla kapatıldı̆̆ örnekler de MÖ II. binyıla dek gözlemlenmektedir. Kenotaph olarak kabul gören mezarlarda dahi, kişiyi simgeleyen masklarda yüzün ağız, göz ve kulak bölümlerinde altın plakalar kullanılmışır ${ }^{5}$. Kültepe'de bulunan göz bantları ${ }^{6}$ ve Anadolu Medeniyetleri Müzesi'nde antik takılar bölümünde teşhirde olan 231 Kat. No. ile envanterlenmiş altın örnek, malzeme dışında form ve ölçü olarak Kibyra buluntusu Kat. No. 27 ile tam bir benzerlik göstermektedir (Fig. 1). Aynı koleksiyondaki 233, 234 ve 238 katalog numaralı, Maraş, Isparta gibi farklı bölgelerden gelmiş Roma İmparatorluk Dönemi'ne tarihlenen oval altın plakalar, gömü törenlerinde cesedin gözlerini kapatmak için göz çukurlarında objeler kullanıldığını kanıtlamaktadır ${ }^{7}$. Ölüm, pek çok kültürde bedenden ayrışan ruhun başka bir dünyaya "göçü" olarak algılanır. Roma Imparatorluk Dönemi'nde, beden-ruh ayrışması ve bir dünyadan diğerine geçiş üzerine literatürde geniş bir boşluk bulunmaktadır. MS III. yüzyıla ait yazıtlarda, bu geçiş "beden dünyada kalır, ruh gökyüzüne katılır=corpus ut terram manere, spiritum celum sequi" veya "in venti aera primum = rüzgarla akar gider" gibi tümcelerle tanımlanmıştır. Bugünkü bilgilerimizle, bu dünya ve öte dünya arasındaki nehirden ölünün ruhunu belli bir ücret karşılığı ölüler diyarına geçirecek olan bir "kayıkçı" figürü, MÖ III. binden itibaren Mısır mitolojisinde de kullanılmaktadır.

Roma dini, kozmopolit imparatorluk yapısı içinde spesifik bir gömü şekli veya ritüeli tanımlamadığından, gömü ritüelleri çok farklıdır ${ }^{8}$ ve bazen çok erken dönemlere ait farklı kültürlerin ritüellerine ait örneklerle de karşılaşmak olasıdır. Bunlardan biri de, mezarlarda iskeletin ağzında, elinde veya yanında bulunan sikkelerin gösterdiği gibi, MÖ V. yüzyıldan itibaren Hellenler, MÖ II. yüzyıldan itibaren de Romalılar tarafından uygulanmış olan bir ritüel, kayıkçı "Kharon'un obolosu'dur". Samsatlı Lukianos "Kharon altını bilmez ve sadece bakır kabul eder" demiş olsa da ${ }^{10}$, pratikte farklı materyaller bu amaçla kullanılmıştır. Örneğin, obolos dışında farklı değerde ve farklı madenden sikkeler, ölünün sadece ağzına değil, gözlerine veya sağ eline de Kharon'un kolay alabilmesi amacıyla yerleştirilmiştir ${ }^{11}$. Styks'ü geçerken Kharon'a verilmek üzere 1/6 drakhme değerindeki obolos tercih edilmişken, zamanla "hayalet sikke" olarak adlandırılan, sikkelerden baskı yöntemiyle alınan kopyalarla üretilmiş ince altın, gümüş gibi metal plakalar da kullanıımıştır ${ }^{12}$.

2005 yııında Parion Nekropolis'inde yapılan kazılarda, üçü iskeletlerin ağızlarında, biri kremasyon kabı içinde olmak üzere, "dilaltı pulu" veya "empresyon sikke" olarak tanımlanan ve Erken Hellenistik Dönem'e tarihlenen; üzerlerinde Apollon ve Helios olabilecek figürler betimli 4

Bonogofsky 2005, 127. Bu geleneğin Afro-Amerikanlarda 19. yüzyıla dek sürmüş olduğu görülmektedir; Combes 1974, 52-61; Larsson 2010, 88.

Witte 1998, 50.

Chapman et al. 2006, 160.

Özgüç 2005, 226 res. 280.

Kaynak: http://www.kulturvarliklari.gov.tr/TR,43404/agiz-ve-goz-bantlari.html

Retief - Cilliers 2006, 129.

Wardle - Wardle 2004, 476; Retief - Cilliers 2006, 138; Vlachou 2012, 365.

Doyen 2012, I vd.

Crummy 2010, 67.

Grinsel 1957, 257-258. 
adet altın obje bulunmuştur ${ }^{13}$. Kharon için mi bırakıldıkları, yoksa mezarlarda bulunan altın takılardan mı kopmuş oldukları tartışması ise sürmektedir. Sikke biçimli bu tip objeler, antikçağda aplik olarak giysi ya da takılarda yaygın olarak kullanıımışı ${ }^{14}$. Aynı gelenekle, giysiler veya takılarda aplik olarak kullanılmak üzere, sikkelerden alınan kalıplarla pişmiş toprak örnekler üretilmiş olması veya ön yüzdeki portrelerin taklit edilmiş olması da mümkündür. Kat. No. 25, YOM 11'de bulunmuştur ve üzerinde, İskender'in pek çok sikkede görülen Zeus Ammon tipi betimlenmiş$\operatorname{tir}^{15}$. Daire formlu aplik altın yaldızla boyanarak, çerçeve içinde bir madalyon şeklinde de kullanılmış olabilir.

Kibyra'da kazılar ilerledikçe, kentin başka bölgelerle, örneğin Suriye ile olan ilişkilerinin kanıtları da yavaş yavaş ortaya çıkmaktadır. YOM $6^{\prime}$ da bulunan bir aryballos'un 7,6 cm yüksekliğine dek, tıpatıp aynısı olan, aynı kalıp ve aynı ustanın elinden çıktığı düşünülebilecek benzeri Metropolitan Müzesi'ndedir ve 1900 yılında Suriye Hauran'dan satın alındığı not düşülmüştür ${ }^{16}$.

Kentin Suriye ile olan direkt ilişkisine başka bir örnek, Antalya Müzesi'nde sergilenen Aurelia Paulina'nın gerdanlığı üzerindeki taşlarda görülmektedir: Suriye kökenli bir soylu olan ve MS II. yüzyıl sonunda Perge'de Artemis rahibesi olduğu bilinen Paulina'nın Antalya Müzesi'ndeki heykeli ve yaptırdığı çeşmenin alınlığındaki yüksek kabartmasındaki betimlemesi, anavatanıyla olan ilişkilerini kuvvetle yansıtmaktadır ${ }^{17}$.

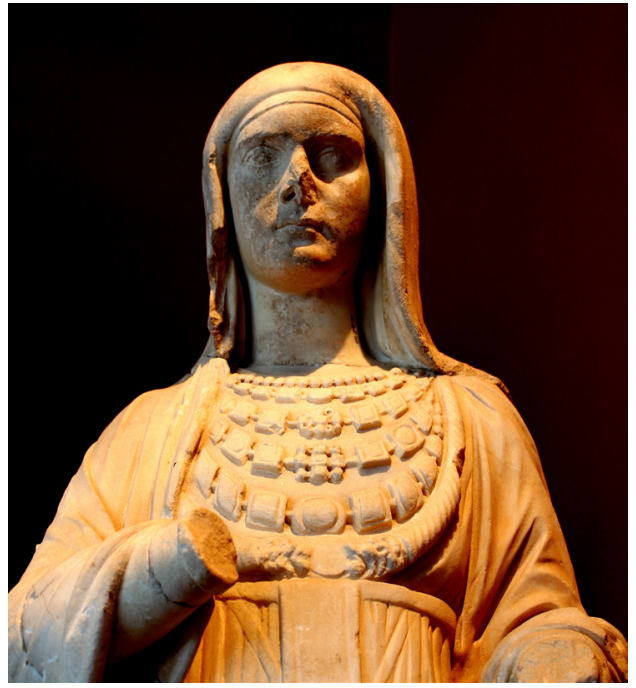

Fig. 2

Paulina'nın göğsündeki, Artemis kültüyle ilişkilendirilen 6 sıralı ağır gerdanlığı oluşturan kare ve oval taşlar, form ve ölçü olarak apliklerle bire bir benzeşmektedir (Fig. 2). Doğal taşlar kullanıldığında gerdanlığın ağırlaşacağı düşünüldüğünde, ortası parlak kırmızı, çevresi altın yaldızlı seramiklerin bu tip gerdanlıklara aplike edildiği düşünülebilir.

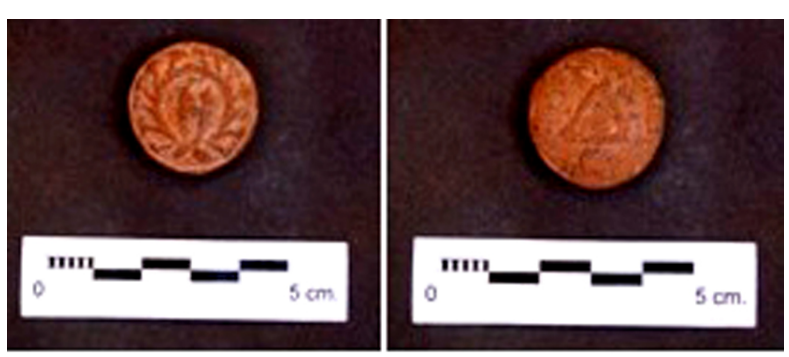

Fig. 3

YOM 11'de ele geçen Kat. No. 4 ile Odeion'da bulunan Kat. No. 26 ve 27 metal örneklerde bulunan delikler de, bu apliklerin iplerle kullanılmıs olduğunu göstermektedir. Ancak 27 örnekten sadece birinde çift delik varken, metal örneklerde tek delik bulunmaktadır. Aurelia Paulina'nın gerdanIığının alttan ikinci sırasının ortasında bulunan apliğin iki yanı delikli olmalıdır ve Kat. No. 4 benzeri bir parçanın burada kullanılmış olması da mümkündür.

Kibyra kazılarında Odeion ve Tiyatro arasındaki alanda 2011 yılında bulunan 2011'22-27 envan-

13 Kasapoğlu 2012, 119 vd; Keleş 2014, 117-118.

14 Keleş 2014, 128 fig. 7; Kovalenko 2015, 26 vd.

15 Fredricksmeyer 1991, 199-200; Dahmen 2007, 11 vd. pl. 8, 1-4.

16 Richter 1915, 196 fig. 516; Demirer 2013, 24-25, 189, A1.

17 Longfellow 2011, 185-186. 
ter numaralı 6 adet pişmiş topraktan tiyatro bileti form olarak benzeşseler de, apliklerden farklıdırlar; ön yüzlerinde bir çelenk, arka yüzlerinde ise oturulacak alanı belirten delta harfi yer almaktadır (Fig. 3).

\section{Sonuç ve Tarihleme}

Kibyra'da bu denli yoğun bir buluntu grubunun sadece MS II. yüzyıl mezarları ve çevresinden bulunmuş olması, eserlerin tiyatro biletleri veya oyun taşları olamayacağını göstermektedir. Belki de bu nedenlerle, benzer karşılaştırma örnekleri bulmak için "göz apliği, tiyatro bileti, oyun taşı" tanımlamalarıyla yapılan literatür taramaları şimdilik yetersiz kalmaktadır.

Benzer buluntularla ilgili yapılan ilk değerlendirmede, oyun taşı olarak kare formlu; madalyon, tiyatro bileti veya aplik olarak tanımlanmış figürlü benzerlerinin başka bölgelerdeki kazılarda veya müzelerin envanterlerinde olabileceği düşünülmüştür. Bulunan tek benzerler Afyon Müzesi'ndedir ve 1960'। yıllarda satın alma yoluyla elde edilmişlerdir. Portreli örneklerden dolayı müze envanterinde de tiyatro bileti olarak tanımlanmalarına rağmen, işlevlerine dair doğrudan bir kanıt bulunmamaktadır. Illginç bir özellik olarak, Afyon örneklerinde de, Kibyra ben-

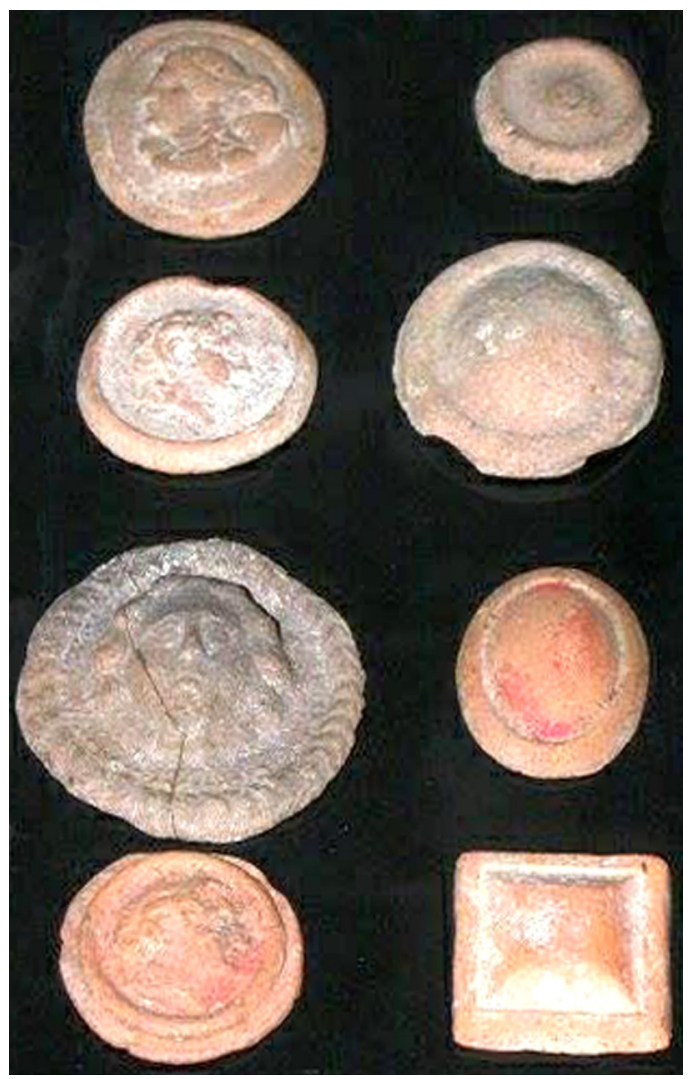

Fig. 4 zerleri gibi dış çerçevede altın yaldız, içte parlak kırmızı boya kullanılmıştır (Fig. 4). Özellikle İskender portreliler de göz önüne alındığında, Afyon ve Kibyra'daki tüm örnekler aynı kalıp ve aynı usta elinden çıkmış görünmektedir.

Apliklerin gerdanlıklar üzerinde kullanılan, altın çerçeveli, yarı değerli taşların imitasyonu olduğu varsayıldığında, gerdanlık parçalarıyla kesin form benzerliğine rağmen buluntuların dağılımı kuşku yaratmaktadır; kısa bir çalışma döneminde ele geçen 25 pişmiş toprak aplik, 7 kontekste dağılmış durumdadır:

$\begin{array}{ll}\text { YOM 9 } & 2 \text { Adet } \\ \text { YOM 10 } & 1 \text { Adet } \\ \text { YOM 11 } & 4 \text { Adet } \\ \text { YOM12 } & 4 \text { Adet } \\ \text { YOM 14 } & 5 \text { Adet } \\ \text { AnIt Mezar } & 5 \text { Adet } \\ \text { Nekropolis Yolu } & 4 \text { Adet } \\ \text { Odeion } & 2 \text { Adet (Metal) }\end{array}$

Tamamı mezarlar, ölü yatakları ve iskeletler yakınında bulunmuş olan aplikler, cesetlerin göz- 
lerini kapatmak için, göz çukurları üzerine yerleştirilmiş olmalıdırlar. Kenarlardaki deliklerde ip kullanıldığı düşünüldüğünde de, bazı örneklerin cesedin yerleştirilmesi veya çürümesi sürecinde göz çukurlarından kaymaması için gözlük benzeri bir düzenekle kullanılmış oldukları varsayılabilir (Fig. 5).

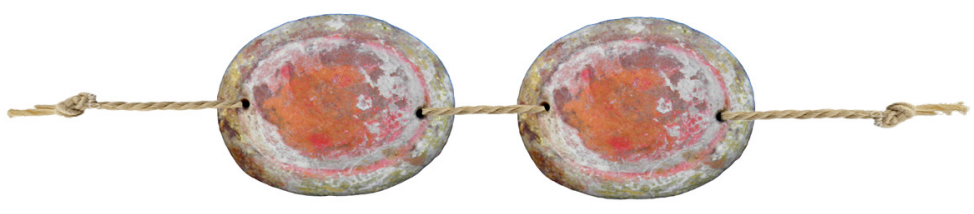

Fig. 5

MS II. ve VI. yüzyıllar arasındaki uzun dönemde yapılaşmalar bulunan Odeion çevresinde yüzey buluntusu olarak ele geçen metal örnekler için kesin bir tarihleme yapmak, kontekstte tabaka verileri olmadığı ve karşılaştırma örnekleri bulunmadığından olanaksızdır. Doğu Nekropolis'teki Anıt Mezar ve çevresindeki iki aile temenosunda bulunan yeraltı oda mezarları ise Erken Antoninuslar Dönemi'nden başlayarak MS II. yüzyıl sonuna dek kullanım görmüştür. Yazıtlardan, temenos'ların Kibyralı varsıl Claudii ve Flavii ailelerine ait oldukları anlaşılmaktadır. Bulunan en geç mezar, yazıtından anlaşılacağı üzere, MS 196 yılına ait olan Eukarios'un lahdidir ${ }^{18}$. Dolayısıyla, nekropol buluntusu apliklerin tarihlenmesinde bir bütün olarak "Erken Antoninuslar - MS II. yüzyıl sonu" önermesi yerinde olacaktır. 


\section{KATALOG}

(Ölçüler cm'dir)

Kat. No. 1

Envanter No: KBR'10-24a

Eserin Yapıldığı Madde: Pişmiş Toprak (P.T.)

Buluntu Yeri: YOM 9, 1. Oda zemin, 2. Ölü yatağı, $-130,-165$.

Ölçüleri: Gen: 4,1; Yük: 3,2; Kal: 0,7

Hamur: 7,5 YR 7/4, 6/4 açık kahverengi

Tanımı: Tekli kalıba basım, üstten oval, yanlar yuvarlatılmış.

Kat. No. 2

Envanter No: KBR'10-24b

Eserin Yapıldığı Madde: P.T.

Buluntu Yeri: YOM 9, 1. Oda zemin, 2. Ölü yatağı, $-130,-165$.

Ölçüleri: Gen: 3,9; Yük: 3,3; Kal: 0,7

Hamur: 7,5 YR 7/4, 6/4 açık kahverengi

Tanımı: Bk. Kat. No. 1

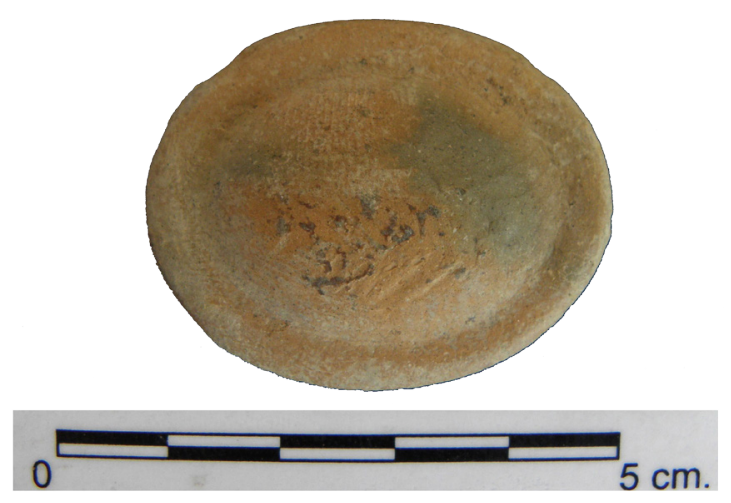

Kat. No. 3

Eserin Yapıldığı Madde: P.T.

Buluntu Yeri: Doğu Nekropolis, Anıt Mezar, Güney Temenos, YOM 10, 2. Oda, Niş Kline, 10.

Ölçüleri: Kal: 0,8; Yük: 2,7; Gen: 3,5
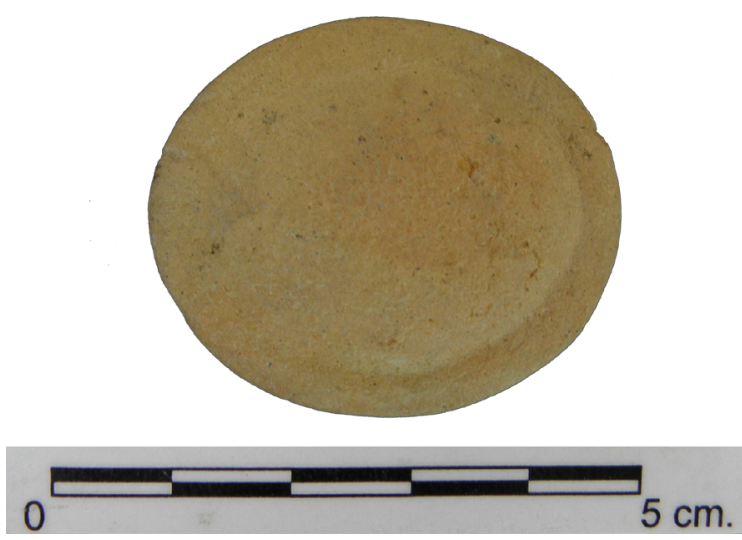

Hamur: 2,5 YR 6/6

Tanımı: Bk. Kat. No. 1. Dış çerçevede altın yaldız kalıntıları olup, iç kısım kırmızı boyalıdır.

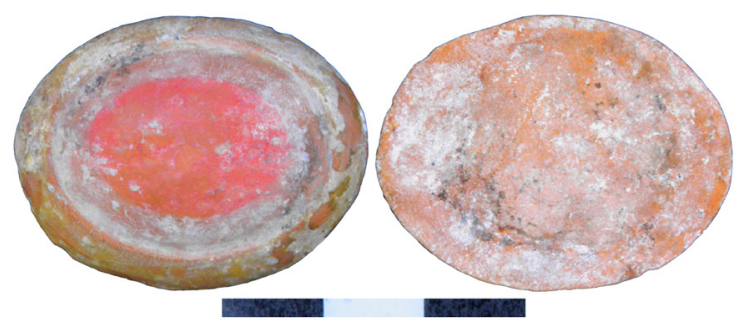


Kat. No. 4

Envanter No: KBR'13-61

Eserin Yapıldığı Madde: P.T.

Buluntu Yeri: Doğu Nekropolis, Anıt Mezar, Güney Temenos, YOM 11, 2. Oda, -140, Ölü Yatağı.

Ölçüleri: Gen: 3,4; Yük: 3; Kal: 0,7

Hamur: 2,5 YR 6/6

Tanımı: Bk. Kat. No. 1

Kat. No. 5

Envanter No: KBR'13-93

Eserin Yapıldığı Madde: P.T.

Buluntu Yeri: Doğu Nekropolis, Anıt Mezar, Güney Temenos 2, K-15, 2. Oda, YOM 12, Güney Ölü Yatağı, 0/-55.

Ölçüleri: Yük: 3,2; Gen: 3,8; Kal: 0,7

Hamur: 7,5 YR 6/3

Tanımı: Bk. Kat. No. 1

Kat. No. 6

Envanter No: KBR'13-95

Eserin Yapıldığı Madde: P.T.

Buluntu Yeri: Doğu Nekropolis, Anıt Mezar, Güney Temenos 2, K-15, 2. Oda, YOM 12, Batı Ölü Yatağı, -45 .
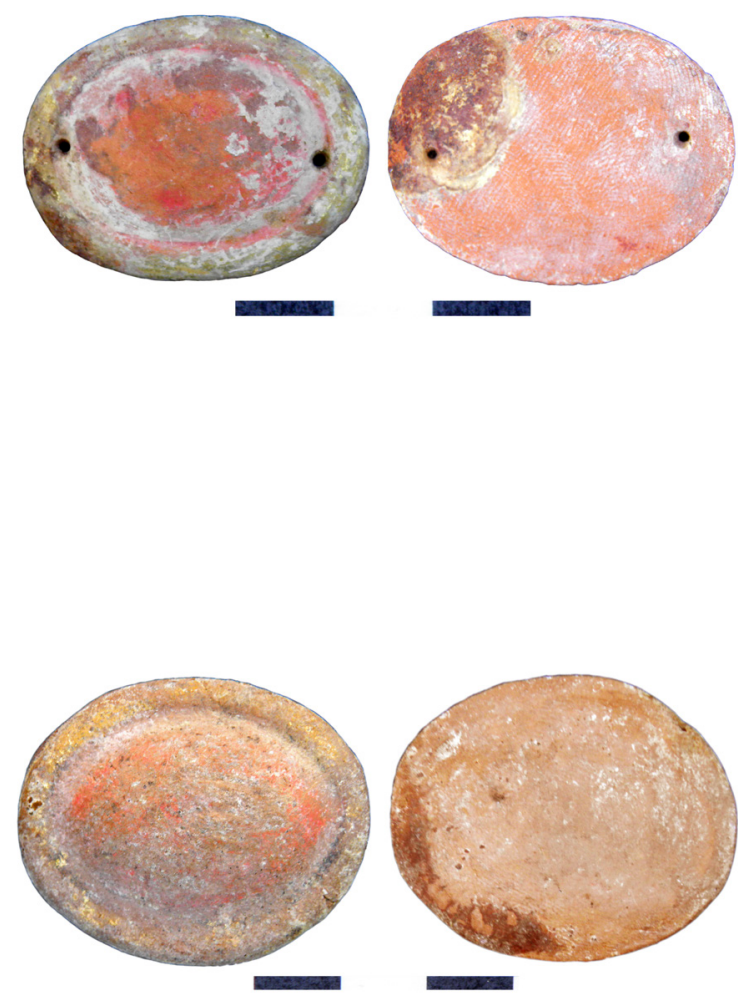
Kat. No. 7

Envanter No: KBR'13-96

Eserin Yapıldığı Madde: P.T.

Buluntu Yeri: Doğu Nekropolis, Anıt Mezar, Güney Temenos 2, K-15, 2. Oda, YOM 12, Batı Ölü Yatağı, 0/-45.

Ölçüleri: Yük: 3,2; Gen: 3,8; Kal: 0,6

Hamur: 7,5 YR 5/4

Tanımı: Bk. Kat. No. 1

Kat. No. 8

Etüd No: KBR'13-39

Eserin Yapıldığı Madde: P.T.

Buluntu Yeri: Doğu Nekropolis, Anıt Mezar, Güney Temenos, Lahit 1, -50.

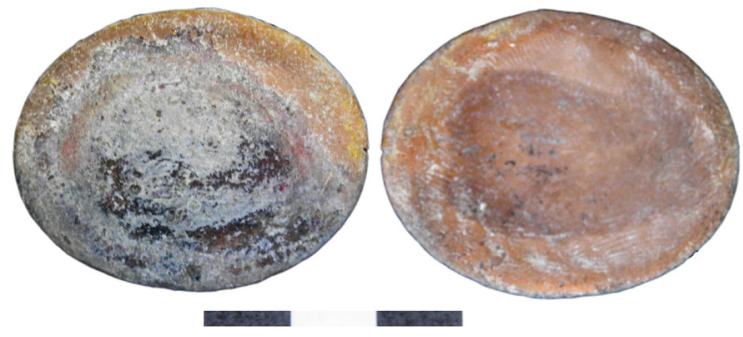

Ölçüleri: Gen: 3,8; Yük: 3; Kal: 0,7

Hamur Rengi: 2,5 YR 6/2

Tanım: Oval formlu, dış bükey, arkası düz kesitli göz apliği, kırık ve eksiktir.

Kat. No. 9

Etüd No: KBR'13-179

Eserin Yapıldığı Madde: P.T.

Buluntu Yeri: Doğu Nekropolis, Anıt Mezar, Batı Ölü Yatağı, Zemin.

Ölçüleri: Gen: 3,6; Yük: 3,5; Kal: 0,7

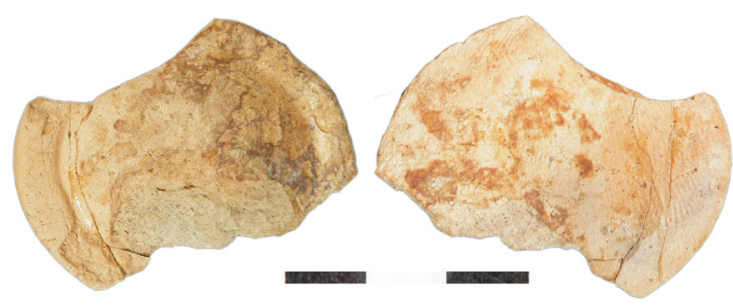

Hamur Rengi: 5 YR 6/6

Tanım: Oval formlu, dış bükey, arkası düz. Uç kısmı kırık ve eksiktir.
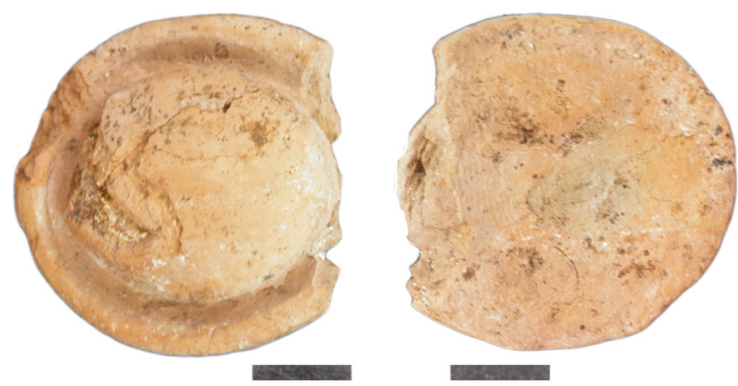
Kat. No. 10

Envanter No: KBR'14-29

Eserin Yapıldığı Madde: P.T.

Buluntu Yeri: Nekropolis Yolu, Kuzey, A1, KM 17'nin Doğu Yanı, -3.60.

Ölçüleri: Gen: 4,5; Yük: 3,8; Kal: 0,6

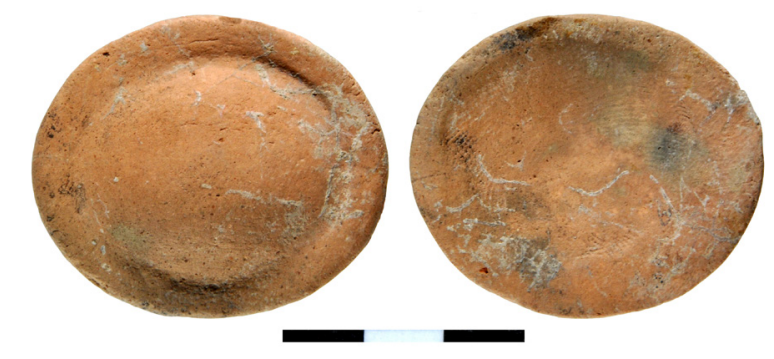

Hamur: 5YR 6/6

Tanımı: Oval formlu, dış bükey, arkası düz.

Kat. No. 11

Envanter No: KBR'14-43

Eserin Yapıldığı Madde: P.T.

Buluntu Yeri: Nekropolis Yolu, Kuzey A1, P2'nin Doğu Önü, İskelet Atığı, -231.

Ölçüleri: Gen: 4; Yük: 3,5; Kal: 0,7

Hamur: 7,5 YR 7/3

Tanımı: Bk. Kat. No. 1

Kat. No. 12

Envanter No: KBR'14-59

Eserin Yapıldığı Madde: P.T.

Buluntu Yeri: Doğu Nekropolis, Anıt Mezar, Güney Açma, YOM 14, Orta alan, -20/-40.

Ölçüleri: Gen: 3,8; Yük: 3; Kal: 0,8

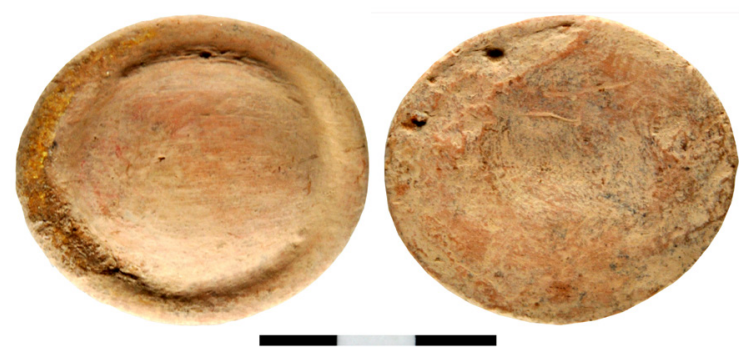

Hamur: 7,5 YR 5/4

Tanımı: Oval formlu, dış bükey, arkası düz. Ön yüzeyde hafif aşınma dışında sağlam.

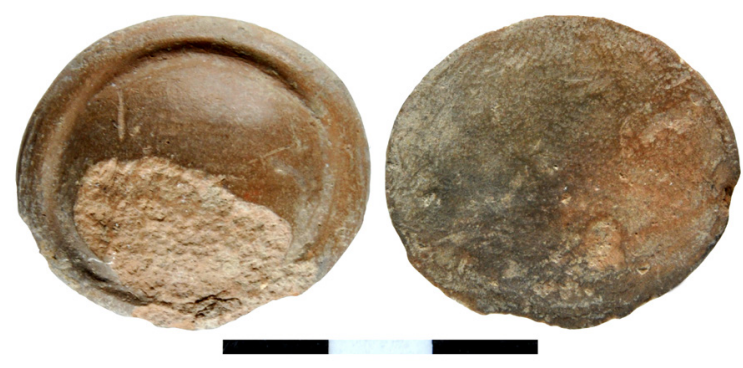


Kat. No. 13

Envanter No: KBR'14-61

Eserin Yapıldığı Madde: P.T.

Buluntu Yeri: Doğu Nekropolis, Anıt Mezar, Güney Açma, YOM 14, Orta alan, -30.

Ölçüleri: Gen: 4,1; Yük: 3,3; Kal: 0,7

Hamur: 7,5 YR 7/6

Tanımı: Bk. Kat. No. 1

Kat. No. 14

Etüd No: KBR'14-9

Eserin Yapıldığı Madde: P.T.

Buluntu Yeri: Nekropolis Yolu, Kuzey A-1, Dolgu.

Ölçüleri: Gen: 4,5; Yük: 3,8; Kal: 1,1
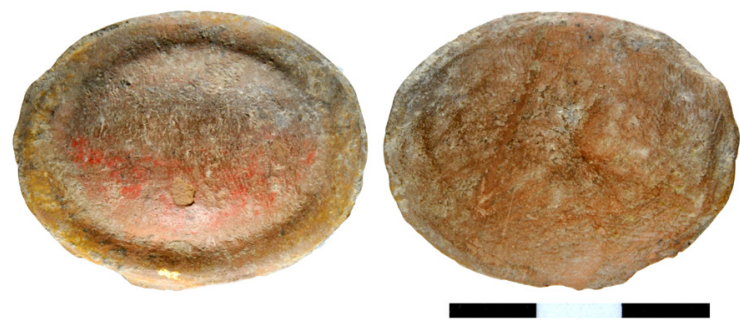

Hamur Rengi: 2,5 YR 6/8

Tanım: Oval formlu, dış bükey, arkası düz.

Kat. No. 15

Etüd No: KBR'14-102

Eserin Yapıldı̆̆ı Madde: P.T.

Buluntu Yeri: Doğu Nekropolis, Anıt Mezar, Güney açma, YOM 14, Orta alan, -20/-40.

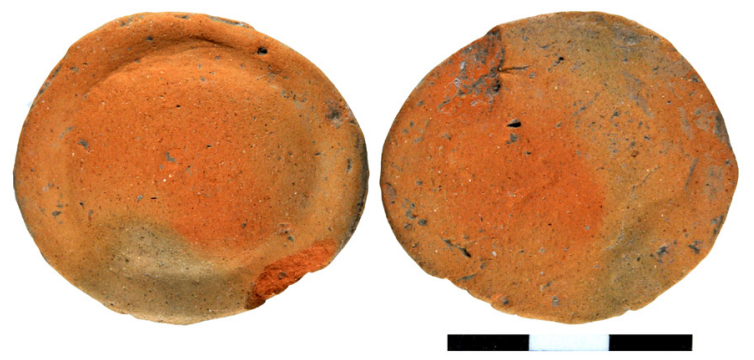

Ölçüleri: Gen: 3,6; Yük: 2,8; Kal: 0,7

Hamur Rengi: 7,5 YR 6/3

Tanım: Bk. Kat. No. 1 Kenarlar kırık ve eksiktir.

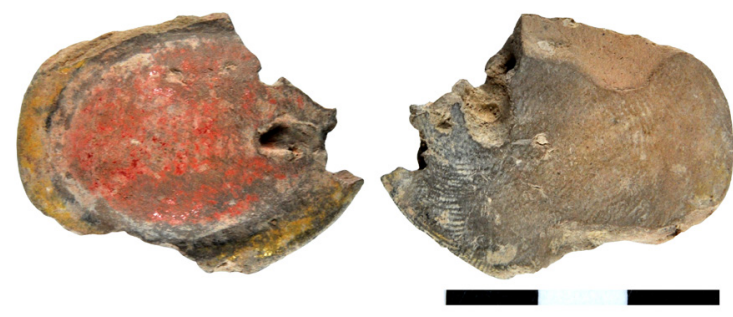


Kat. No. 16

Envanter No: KBR'13-59

Eserin Yapıldığı Madde: P.T.

Buluntu Yeri: Doğu Nekropolis, Anıt Mezar, Güney Temenos, YOM 11, 2. Oda, -140, Ölü Yatağı.

Ölçüleri: Gen: 3; Yük: 3; Kal: 0,5

Hamur: 7,5 YR 6/4

Tanımı: Kare formlu göz apliği. İçteki kare kısımda az miktarda kırmızı boya izleri görülmektedir.

Kat. No. 17

Envanter No: KBR'13-60

Eserin Yapıldığı Madde: P.T.

Buluntu Yeri: Doğu Nekropolis, Anıt Mezar, Güney Temenos, YOM 11, 2. Oda, -140, Ölü Yatağı.

Ölçüleri: Gen: 4; Yük: 4; Kal: 0,5

Hamur: 5 YR 6/3

Tanımı: Bk. Kat. No. 16

Kat. No. 18

Envanter No: KBR'13-94

Eserin Yapıldığı Madde: P.T.

Buluntu Yeri: Doğu Nekropolis, Anıt Mezar, Güney Temenos 2, K-15, 2. Oda, YOM 12, Batı Ölü Yatağı, 0/-40.

Ölçüleri: Gen: 3,5; Yük: 3,5; Kal: 0,7

Hamur: 7,5 YR 5/4

Tanımı: Bk. Kat. No. 16
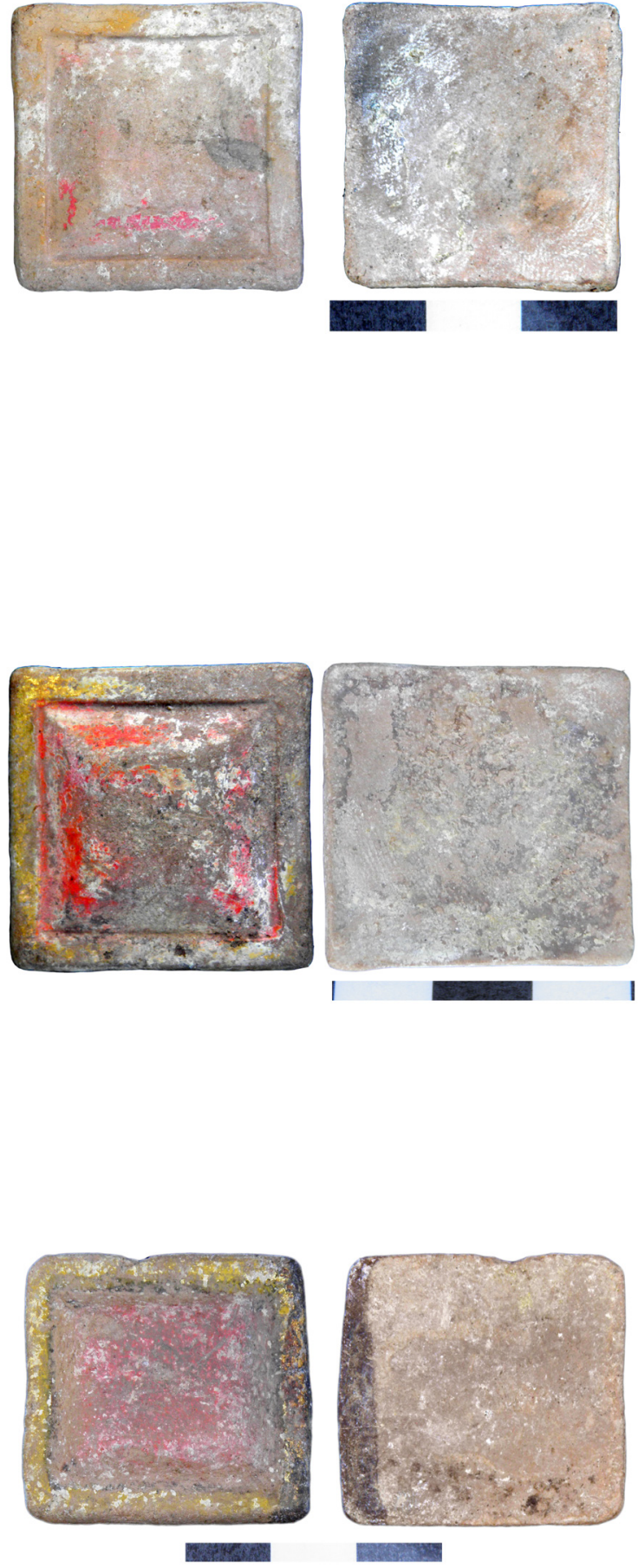
Kat. No. 19

Envanter No: KBR'13-124

Eserin Yapıldığı Madde: P.T.

Buluntu Yeri: Doğu Nekropolis, Anıt Mezar, Güney Temenos 2, K-15, 3. Lahit, Dolgu.

Ölçüleri: Gen: 3; Yük: 3,2; Kal: 0,7
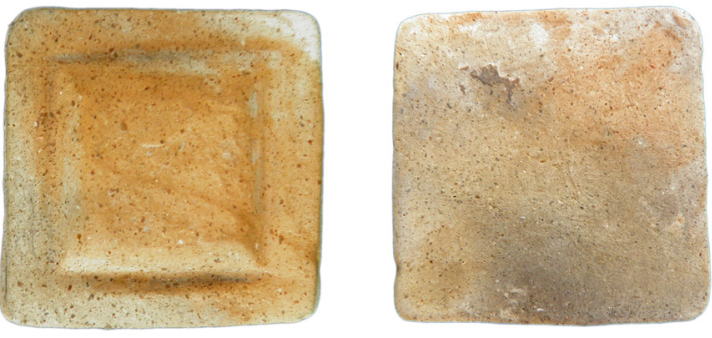

Hamur: 5 YR 6/6

Tanımı: Bk. Kat. No. 16

Kat. No. 20

Etüd No: KBR'13-176

Eserin Yapıldığı Madde: P.T.

Buluntu Yeri: Doğu Nekropolis, Anıt Mezar, 1. Oda, Orta Alan, Zemin.

Ölçüleri: Gen: 3; Yük: 2,6; Kal: 0,7

Tanım: Bk. Kat. No. 16. Bir kenarı kırık ve eksiktir.

Kat. No. 21

Etüd No: KBR'13-180

Eserin Yapıldığı Madde: P.T.

Buluntu Yeri: Doğu Nekropolis, Anıt Mezar, 1. Oda, Güney Kline, -20.

Ölçüleri: Gen: 3,2; Yük: 3,2; Kal: 0,7

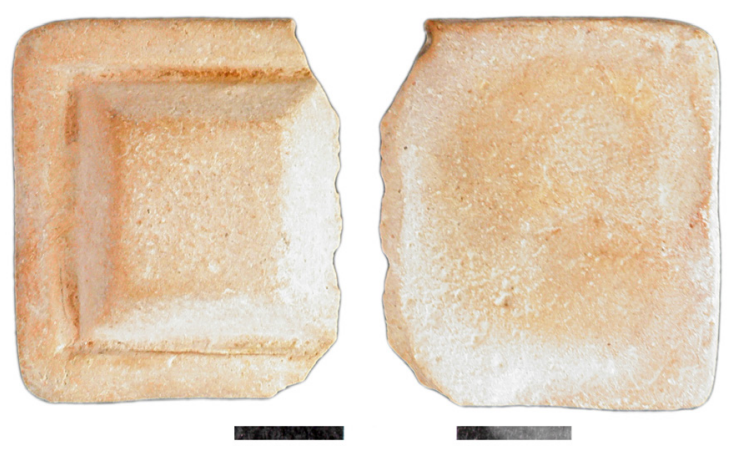

Hamur Rengi: 7,5 YR 6/4

Tanım: Bk. Kat. No. 16. Bir köşesi kırık ve eksiktir.
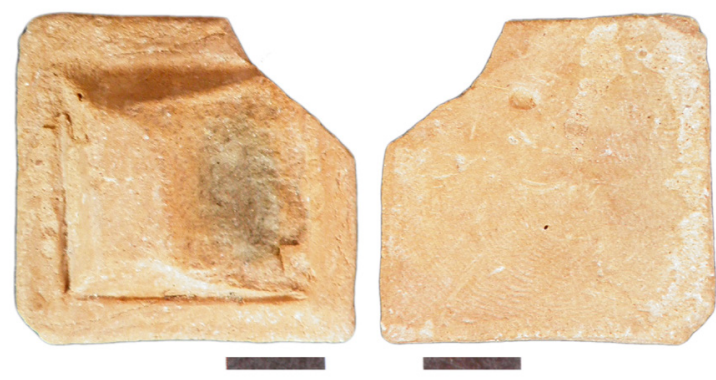
Kat. No. 22

Envanter No: KBR'14-55

Eserin Yapıldığı Madde: P.T.

Buluntu Yeri: Nekropolis Yolu, Kuzey A2, KM 29, P3 Kuzeyi, -103.

Ölçüleri: Gen: 3,2; Yük: 3,2; Kal: 0,6
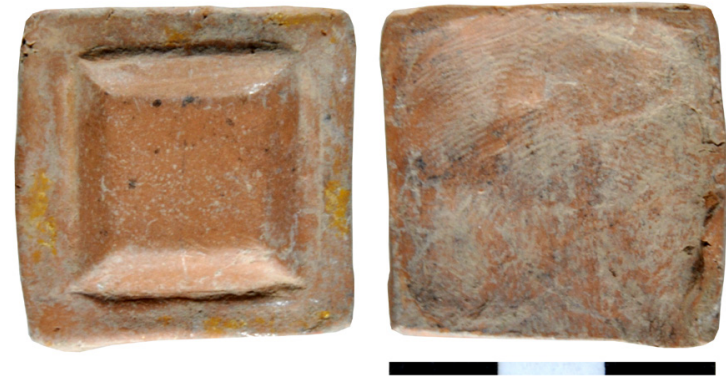

Tanımı: Bk. Kat. No. 16.

Kat. No. 23

Envanter No: KBR'14-60

Eserin Yapıldığı Madde: P.T.

Buluntu Yeri: Doğu Nekropolis, Anıt Mezar, Güney Açma, YOM 14, Orta alan, -20/-40.

Ölçüleri: Gen: 3,2; Yük: 3,2; Kal: 0,6

Hamur: 7,5 YR 5/4

Tanımı: Bk. Kat. No. 16.

Kat. No. 24

Etüd No: KBR'14-103

Eserin Yapıldığı Madde: P.T.

Buluntu Yeri: Doğu Nekropolis, Anıt Mezar, Güney açma, YOM 14, Orta alan, 0/-20.

Ölçüleri: Gen: 2,8; Yük: 3,2; Kal: 0,7

Hamur Rengi: 5 YR 6/4
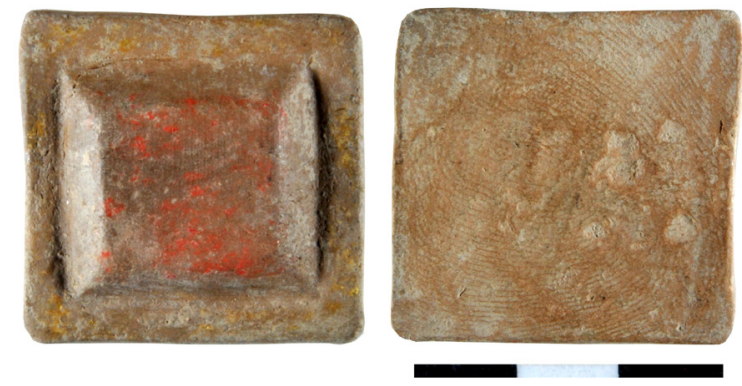

Tanım: Bk. Kat. No. 16. Kenarı kırık ve eksiktir.
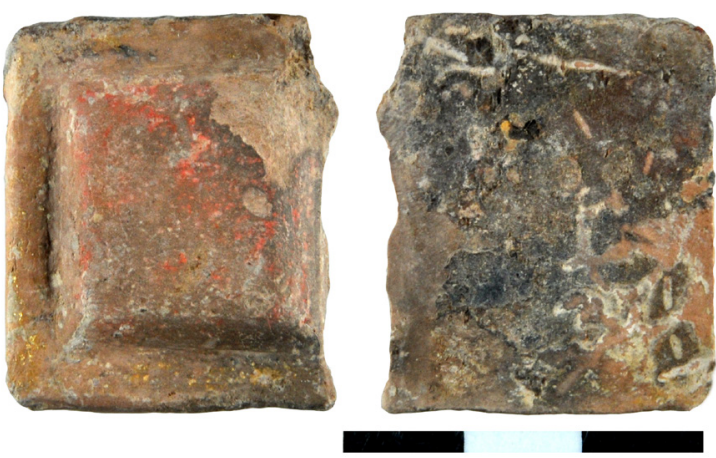
Kat. No. 25

Envanter No: KBR'13-62

Eserin Yapıldığı Madde: P.T.

Buluntu Yeri: Doğu Nekropolis, Anıt Mezar, Güney Temenos, YOM 11, 2. Oda, -140, Ölü Yatağı.

Ölçüleri: Çap: 3,2; Kal: 0,6

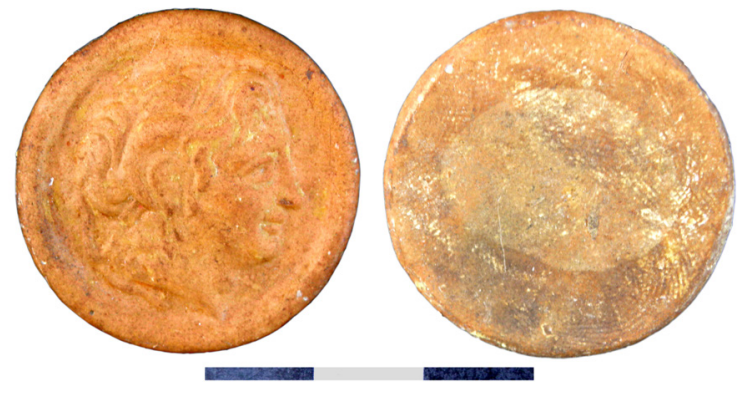

Hamur: 7,5 YR 5/6

Tanımı: Daire formlu, arkası düz. Üzerindeki portrede başı sağa dönük, Büyük İskender'in Zeus Ammon tipi betimlenmiştir.

Kat. No. 26

Etüd No: KBR' 13-05

Eserin Yapıldığı Madde: Bakır Alaşım

Buluntu Yeri: Odeion, Yüzey.

Ölçüleri: Gen: 2; Yük: 1,5; Kal: 0,5

Tanım: Göz biçimli objenin içerisinde eşmerkezli ovoid yivler, ince kenarda tek delik bulunmakta.

Kat. No. 27

Etüd No: KBR'12-74

Eserin Yapıldığı Madde: Bakır Alaşım

Buluntu Yeri: Odeion, Stoa Kuzey Bölüm, Geç Dönem Yapı Grubu, -60.

Ölçüleri: Çap: 3,5; Kal: 0.0,5

Tanımı: Daire formlu içbükey levha. Kenarda

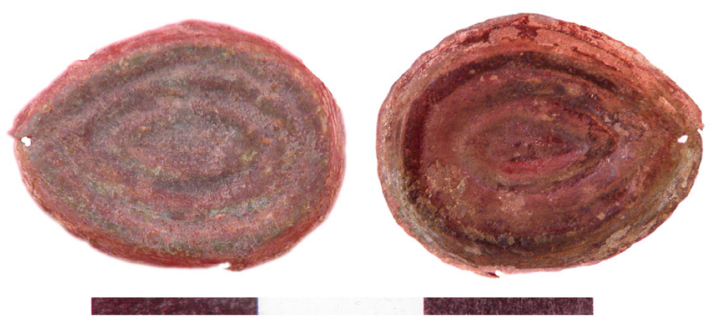
tek delik bulunmakta.

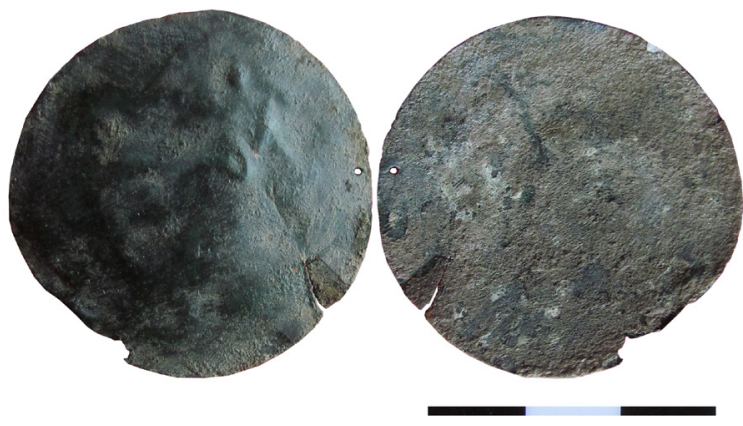


Bonogofsky 2005

Chapman et al. 2006

Combes 1974

Crawford 2004

Crummy 2010

Dahmen 2007

Demirer 2013

Doyen 2012

Fredricksmeyer 1991

Grinsel 1957

Kasapoğlu 2012

Keleş 2014

Kovalenko 2015

Larsson 2010

Longfellow 2011

Özgüç 2005

Özüdoğru 2014a

Özüdoğru 2014b

Retief - Cilliers 2006

Richter 1915

Şimşek 2013

Vlachou 2012

Wardle - Wardle 2004

Witte 1998

\section{BIBLIYOGRAFYA}

M. Bonogofsky, "A Bioarchaeological Study of Plastered Skulls from Anatolia: New Discoveries and Interpretations". International Journal of Osteoarchaeology 15 (2005) 124-135.

J. Chapman, T. Higham, V. Slavchev, B. Gaydarska - N. Honch, "The Social Context of the Emergence, Development And Abandonment of the Varna Cemetery, Bulgaria". European Journal of Archaeology 9 (2006) 159-183.

J. D. Combes, "Etnography, Archaeology and Burial Practices Among South Carolina Blacks". Ed. S. South, The Conference on Historic Site Archaeology. South Carolina (1974) 52-61.

S. Crawford, "Votive Deposition, Religion and the Anglo-Saxon Furnished Burial Ritual". World Archaeology 36/1 (2004) 87-102.

N. Crummy, "Bears and Coins: The Iconography of Protection in Late Roman Infant Burials". Britannia 41 (2010) 37-93.

K. Dahmen, The Legend of Alexander the Great on Greek and Roman Coins. New York 2007.

Ü. Demirer, Kibyra Metal Buluntuları. Yayımlanmamış Doktora Tezi, Akdeniz Üniversitesi. Antalya 2013.

J. M. Doyen, "The Charon's Obel: Some Methodological Reflexions". The Journal of Archaeological Numismatics 2 (2012) I-XVIII.

E. A. Fredricksmeyer, "Alexander, Zeus Ammon, and the Conquest of Asia". Transactions of the American Philological Association 121 (1991) 199-214.

L. V. Grinsel, "The Ferryman and His Fee: A Study in Ethnology, Archaeology and Tradition". Folklore 68/1 (1957) 257-269.

H. Kasapoğlu, "Nekropol”. Ed. C. Başaran, Antik Troas'ın Parlayan Kenti Parion. İstanbul (2012) 107-136.

V. Keleş, “Parion Nekropolü'nde ele geçen Dört Altın Obje Üzerine Yeni Bir Değerlendirme". Olba XXII (2014) 117-128.

S. A. Kovalenko, "Ancient Coin-Shaped Appliques in the Northern Black Sea Littoral". Coins \& Medals III (2015) 16-28.

L. Larsson, "A Double Grave with Amber and Bone Adornments at Zvejniieki in Northern Latvia". Archaeologica Baltica 13 (2010) 80-89.

B. Longfellow, Roman Imperialism and Civic Patronage: Form, Meaning and Ideology in Monumental Fountain Complexes. Cambridge 2011.

T. Özgüç, Kültepe, Kanis/Nesa. İstanbul 2005.

Ş. Özüdoğru, "Kibyra'dan Hellenistik Dönem'e Ait Yeni Veriler Üzerine Değerlendirmeler". Cedrus II (2014) 171-188.

Ş. Özüdoğru, "2013 Yılı Kibyra Çalışmaları”. ANMED 12 (2014) 55-61.

F. P. Retief - L. Cilliers, "Burial Customs and the Pollution of Death in Ancient Rome: Procedures and Paradoxes". Acta Theologica 26/2 (2006) 128-146.

G. M. A. Richter, Greek, Roman and Etruscan Bronzes. New York 1915.

M. Şimşek, Kibyra Yeraltı Oda Mezarları: Mimari ve Tipoloji. Yayımlanmamış Yüksek Lisans Tezi, Süleyman Demirel Üniversitesi. Isparta 2013.

V. Vlachou, "Death and Burial in the Greek World". Addeddum to Vol. VI. ThesCRA VIII (2010) 363-384.

K. A. Wardle - D. Wardle, "Glimpses of Private Life: Roman Rock cut Tombs of the First and Second Centuries AD at Knossos". BSA 12 (2004) 473-480.

R. Witte, "Heinrich Schliemann-ein pathologischer Lügner?". Gegenworte Heft 2 (1998) 50-51. 